\title{
The effect of a fat-burner and a marine peptide hydrolysate supplement on fat metabolism, during endurance exercise at the Fat ${ }_{\max }$ intensity
}

\begin{abstract}
Background: Obesity is the ultimate result of an imbalance between energy intake and energy expenditure. Currently, research has been focusing on specific food ingredients, which may have favorable effects on human metabolism and especially fat kinetics during exercise. Therefore, the purpose of this study was to examine the efficacy of a commercially available 'fat-burner' (Thermobol), containing a mixture of some of the aforementioned thermogenic ingredients, as well as a commercially available fish protein hydrolysate (Nutripeptin ${ }^{\mathrm{TM}}$ ), on enhancing fat metabolism during submaximal exercise, at the intensity which elicits maximal fat oxidation rates $\left(\mathrm{Fat}_{\text {max }}\right)$.
\end{abstract}

Methods: In a randomized, double-blind crossover study design, 7 obese (BMI $>30 \mathrm{~kg} \mathrm{~m}^{-2}$ ), male participants completed a graded treadmill-exercise preliminary testing, followed by three experimental trials. The trials consisted of 60 -min treadmill task corresponding to the Fat intensity (speed and incline gradient), determined by the preliminary testing. Four hours and $1 / 2$ hours before the trials, the participants ingested 3 capsules of placebo, 3 tablets of Thermobol, or 6 capsules of Nutripeptin ${ }^{\mathrm{TM}}$.

Results: During the three experimental trials, the absolute fat $\left(\mathrm{gmin}^{-1}\right)$ and carbohydrate $\left(\right.$ gmin $\left.^{-1}\right)$ oxidation rates did not differ significantly between the three supplements. Energy expenditure $\left(\mathrm{kcalmin}^{-1}\right)$ was significantly higher in the Thermobol supplement, compared to placebo [mean (S.D); $8.03(1.46)$ Vs $8.24(1.39) ; \mathrm{p}=.042)$ ], whereas in the Nutripeptin ${ }^{\mathrm{TM}}$ supplement, it was not (8.21 (1.46) Vs $8.0(1.46) ; \mathrm{p}=.073)$. Heart rate (bpm), RPE, blood glucose $\left(\mathrm{mmol} \mathrm{L}^{-1}\right)$ and blood lactate $\left(\mathrm{mmol} \mathrm{L}^{-1}\right)$ responses were not found to be significantly different across the three experimental conditions.

Conclusion: Although Thermobol appeared to influence metabolism during submaximal exercise at the Fatmax intensity, Nutripeptin ${ }^{\mathrm{TM}}$ did not provide any metabolic effect.
Volume 2 Issue 4 - 2015

\section{Michail Konstantinidis}

Department of Sport and Exercise Science, University of Portsmouth, Greece

Correspondence: Michail Konstantinidis, Department of Sport and Exercise Science, University of Portsmouth, Greece, Email micfede4@gmail.com

Received: March 03, 2015 | Published: May 20, 2015

Keywords: obesity, Thermobol, nutripeptin ${ }^{\text {tm }}$, Fat ${ }_{\text {max }}$ intensity

Abbreviations: EE, energy expenditure; GTE, green tea extract; RER, respiratory exchange ratio; FPH, fish protein hydrolysate; FFA, free fatty acid; PROCHO, proteins, carbohydrates; SD, standard deviation; BMI, body mass index; EHHQ, exercise and health history questionnaire; IQR, interquartile range: ANOVA, analysis of variance; HR, heart rate; ANP, atrial natriuretic peptide; COMT, catechol-o-methyltransferase; NE, norepinephrine; UCPs, uncoupling proteins; cAMP, cyclic amino-mono-phosphate; SNS, sympathetic nervous system

\section{Introduction}

Excess adiposity and particularly the accumulation of immoderate abdominal fat in the body, is known as obesity. ${ }^{1}$ Over the last two decades, research has been focusing on different anti-obesity strategies, among which the ingestion of specific food constituents, which may have favorable effects on human metabolism. ${ }^{2}$ Therefore, several bioactive food ingredients, including capsaicin (hot red pepper), caffeine (coffee, tea, etc.) and catechins (green tea extracts) have been proposed to be capable of enhancing thermogenesis and thereby daily energy expenditure (EE). ${ }^{3}$ Since their effect has been partly attributed to an increment in fat oxidation, there has been a growing interest in nutritional supplements which are alleged to increase fat metabolism, hence their commercial name 'fat-burners' (Figure 1). ${ }^{4}$

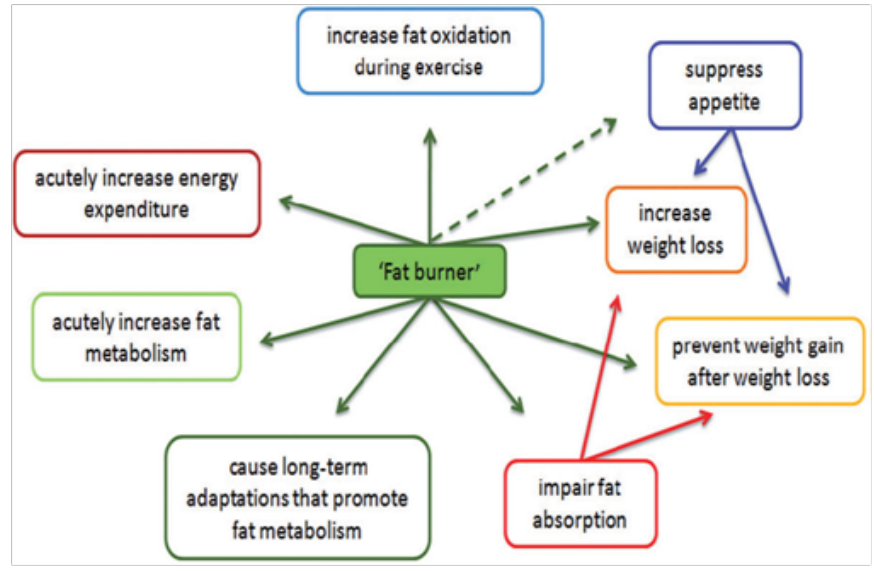

Figure I Potential actions of 'fat-burner' supplements on energy balance.

Thermobol, namely one of the supplements tested in this study is a commercially available 'fat-burner', containing a mixture of ingredients (caffeine, green tea extract, capsaicin, L-tyrosine, bitter orange peel, Guarana extract), which are claimed to possess supplementary effects on fat metabolism, when combined together. ${ }^{5}$ Among Thermobol's components, the well-studied are caffeine, green 
tea extracts (GTE) and secondary capsaicin. In regard to the remainder ingredients, the evidence is scarce and thus any conclusions about their effects are tentative. ${ }^{6-8}$

Although, there is a plethora of studies which have demonstrated the effectiveness of caffeine-GTE blends, in significantly increasing EE and/or fat oxidation, ${ }^{9,10}$ the evidence remains mixed. ${ }^{11}$ Caffeine has been shown to increase EE and fat oxidation during rest and lowintensity exercise, although its effects on fat metabolism are small and seem to be diminished during moderate-to-high-intensity exercise. ${ }^{5}$ Furthermore, GTE may be capable of raising fat oxidation during rest and exercise as well, ${ }^{12}$ although as with caffeine the effect is relatively small.

The results of a recent meta-analysis showed that catechincaffeine mixtures have a significant effect on boosting EE as well as fat oxidation, compared to placebo and/or caffeine alone. ${ }^{11}$ Venables et al., ${ }^{13}$ investigated the acute effects of GTE ingestion on substrate metabolism during moderate-intensity exercise in healthy women and found that fat oxidation rates were $17 \%$ higher $(p<.001)$ after GTE ingestion, compared to exercise alone.

When green tea catechins along with a small amount of caffeine were ingested by overweight and obese subjects, over an 8 -week exercise training period, fat oxidation rates were $37 \%$ and $32 \%$ higher $(\mathrm{p}<.001)$, respectively, compared to placebo. ${ }^{14}$ Likewise, in two recent studies the daily consumption of epigallocatechin-3-gallate (EGCG; the most abundant and biologically active among green tea catechins) alone, increased fat oxidation in overweight and obese males by $41.5 \%$ and $49.4 \%$, respectively, during the postprandial state. ${ }^{15}$ Conversely, Gregersen et al. ${ }^{3}$ reported no significant acute effect of GTE along with caffeine on EE, respiratory exchange ratio (RER) and substrate oxidation. Similarly, Hill et al., ${ }^{16}$ found that in over weight/obese women, the daily ingestion of $300 \mathrm{mg}$ EGCG, superimposed on a 12week moderate-intensity exercise programme, did not have evident effects on body composition.

The findings about capsaicin are also equivocal, since there are studies which have demonstrated that capsaicin supplementation favorably interferes with substrate utilization (lower RER values, compared to placebo) and enhances thermogenesis in general, ${ }^{17-19}$ while others have reported no significant effects.,20 Although research for biologically active compounds from marine sources remains a relatively new field, marine-derived molecules possess many biological properties, which enable them to be utilized towards various human health benefits..$^{21,22}$ Marine peptides, depending on their amino acid composition and sequence, ${ }^{23}$ have been found to hold several physiological functions, namely antioxidant, antihypertensive, antithrombotic and hypocholesterolemic activity. ${ }^{24-26}$

Liaset et al. ${ }^{27}$ observed that rats which were fed with fish protein hydrolysate $(\mathrm{FPH})$ reduced their visceral fat, compared to those which were administered soy protein or casein, suggesting a metabolic shift towards free fatty acid (FFA) oxidation. This observation triggered the scientific interest towards the appliance of FPH in the context of endurance exercise in humans. ${ }^{28}$ However, Vegge et al., ${ }^{29}$ did not report significant difference among the RER values ( $>$.05) of three different beverages, containing carbohydrates $(\mathrm{CHO})$, proteins, carbohydrates (PROCHO) and FPH (Nutripeptin ${ }^{\mathrm{TM}}$ ), protein and carbohydrates (NpPROCHO), during 120-min cycling, in well-trained male cyclists. Siegler et al., ${ }^{28}$ employed the same beverages during a 90 -min cycle task in healthy males and they found significantly higher RER values in the group ingesting the PROCHO solution, compared to the other two (mean difference .003, $\mathrm{p}<.001$ ).

From the last two studies aforementioned, it emerges that any potential metabolic effects of FPH on human metabolism and especially fat metabolism, remains to be determined. Therefore, the purpose of this study is to test the metabolic effects of an FPH supplement (Nutripeptin ${ }^{\mathrm{TM}}$ ) and a thermogenic agent (Thermobol), compared to a placebo. It is hypothesized that Nutripeptin ${ }^{\mathrm{TM}}$ as well as Thermobol will raise fat metabolism, during submaximal exercise at an intensity which elicits maximal fat oxidation rates (Fat ${ }_{\max }$ intensity), compared to placebo.

\section{Methods}

\section{Participant characteristics}

Ten apparently healthy obese males volunteered to participate in the study and had the following characteristics: median (IQR) age of 23 (5) years; mean (S.D) body mass index (BMI) of 36.9 (3.6) $\mathrm{kg} \mathrm{m}^{-2}$; and mean (S.D) waist circumference of $108(10.5) \mathrm{cm}$. All participants signed an informed consent form as well as an Exercise and Health History Questionnaire (EHHQ), prior to participation. The investigation was approved by the Biosciences Research Ethics Committee on behalf of the University of Portsmouth and was conducted in accordance with the Declaration of Helsinki (2008). Two volunteers were excluded, since they did not meet the inclusion requirements of the study and one dropped-out because of an injured knee.

\section{Experimental protocol}

The study was designed and carried out in a randomized, doubleblinded and crossed-over manner. The effects of ingesting each of three different supplements (placebo, Thermobol and Nutripeptin ${ }^{\mathrm{TM}}$ ) on fat oxidation rates were tested on three different test days, separated by at least one day and no more than ten days. Preliminary testing consisted of an incremental treadmill (Woodway Pro-XL treadmill) exercise, conducted in order to determine the speed $\left(\mathrm{km} \mathrm{h}^{-1}\right)$ and incline gradient (\%), which aimed to elicit the maximal fat oxidation $\left(\right.$ Fat $\left._{\mathrm{max}}\right)$, for each participant. The three experimental trials consisted of 60 -min treadmill walk at the Fat ${ }_{\text {max }}$ intensity. Prior to each trial, participants ingested one of the three supplements, four hours and thirty minutes before the commencement of the test, respectively. For each participant, the three tests were performed at approximately the same time of the day to avoid circadian variance. All walking tests were performed on the same treadmill, under similar environmental conditions (temperature: $21.0 \pm 1.2^{\circ} \mathrm{C}$; humidity: $40 \pm 6 \%$; barometric pressure: $761 \pm 8 \mathrm{mmHg}$ ).

\section{Supplements}

The placebo supplement contained 500mg maltodextrin powder, per capsule (470mg maltodextrin). The Thermobol supplement contained $325 \mathrm{mg}$ bitter orange peel (Citrus Aurantium), 300mg L-tyrosine, $153 \mathrm{mg}$ caffeine, 100mg GTE (90\% polyphenols), 12mg Guarana seed powder and $120 \mu \mathrm{g}$ capsaicin extract from hot cayenne pepper, per tablet. The Nutripeptin ${ }^{\mathrm{TM}}$ (Nutrimarine, Life Science AS, Bontelabo 2, Bergen, 5003, Norway) supplement contained 500mg hydrolysed proteins (peptides) from fish fillets, per capsule.

For the placebo and the Thermobol supplement, participants ingested two capsules four hours before and one, thirty minutes 
before the trials, whereas for the Nutripeptin ${ }^{\mathrm{TM}}$ supplement, they ingested three capsules, both four hours and thirty minutes before. The identity of the supplements was not at any time revealed to either the participants or to the principal researchers. Furthermore, because the participants had no previous experience with the supplements, they could not identify them.

\section{Preliminary trial}

On the participants' first visit, their weight $(\mathrm{kg})$ was recorded by Seca digital weighing scales and their height $(\mathrm{cm})$ by a stadiometer (Harpender, Body Care, and Kenilworth, UK). From these measurements, their BMI was calculated, using the BMI equation: $\left[\mathrm{BMI}=\right.$ weight $(\mathrm{kg}) /$ height $\left.\left(\mathrm{m}^{2}\right)\right]$. The waist girth of the participants was also measured, using a measuring tape. Particularly, the measurement was taken on bare skin, at the narrowest part of the trunk, during a normal exhalation. Subsequently, participants performed an incremental treadmill walk test, for the determination of the intensity (speed and incline gradient) which elicits maximal fat oxidation rates ( $\mathrm{Fat}_{\text {max }}$ intensity), as previously described by Venables et al. ${ }^{30}$ The test was initiated with 1 -min walking at a speed of $3.0 \mathrm{~km}$ $\mathrm{h}^{-1}$ and an incline gradient of $0 \%$. Every subsequent minute, speed was increased by $1 \mathrm{~km} \mathrm{~h}^{-1}$, until the point when participants stated that they could 'comfortably' walk at this pace for one hour (stage 1). After that point, incline gradient was increased by $1 \%$ every minute, until an RER of 1.0 was attained and the test was terminated (stage 2). The Fat ${ }_{\max }$ intensity for each participant was worked out from the fat oxidation rates $\left(\mathrm{g} \mathrm{day}^{-1}\right)$ data set, obtained by an automated gas analysis system (Cosmed, K4b2, Italy). The mean speed and incline gradient were $5.0 \mathrm{~km} \mathrm{~h}^{-1}$ and $1 \%$, respectively. Heart rate (HR) was measured continuously throughout the preliminary test, using a HR monitor (Polar Vantage NV, Polar Electro Oy, Kempele, Finland). Rating of Perceived Exertion data (RPE; 6-20 scale) was also collected every minute during the test.

\section{Experimental trials}

Participants were instructed to maintain the same dietary and fluid intake, prior to the experimental trials. All participants were provided with a food diary to record food and fluid consumed 24hours prior to coming into the laboratory for their first experimental trial and in order to be able to replicate this diet for the subsequent trials. They were also instructed to refrain from alcohol, caffeine and exercise for 24 hours prior to all visits. On each of the three trials, participants performed 60-min of walking at the Fat ${ }_{\max }$ intensity. They reported to the lab having consumed a standardized meal, comprising of two slices of toast with jam, two boiled eggs, one cup of orange juice and water. EE $\left(\mathrm{kcal} \mathrm{h}^{-1}\right)$, fat and $\mathrm{CHO}$ oxidation rates $\left(\mathrm{g} \mathrm{h}^{-1}\right)$ were measured, using the Cosmed metabolic system. Resting data, having the participants seated, was also recorded over a 5-minute period, before the commencement of the exercise. HR was continuously recorded throughout, using a HR monitor. RPE was recorded every five minutes during each trial. Additionally, at $0,15,30$ and 50 minutes, blood samples were collected through a finger prick. All blood samples were obtained aseptically from the fingertip via lancet (Accu-Chek Safe T-Pro Plus single-use sterile lancets, Roche Diagnostics, Mannheim, Germany) and collected in $20 \mu \mathrm{L}$ electrolyte balanced heparin coated capillary tubes (Radiometer, West Sussex, UK). Samples were immediately analysed for whole blood glucose and lactate (Biosen C-Line Sport analyzer, manufacturer).

\section{Statistical analysis}

All statistical analyses were conducted using IBM SPSS Statistics
20 (SPSS Inc, Chicago, IL). Central tendency and dispersion of the sample data are reported as the mean and standard deviation (SD) for normally distributed data and the median and interquartile range (IQR) otherwise. Normality was checked using the Skewness and Kurtosis normality tests. Comparisons of means over the 60-min exercise period and across the conditions, were performed using repeated measures one-way and two-way ANOVA. Significant differences identified by the ANOVA, were analysed using paired samples t-test. Two-tailed statistical significance was accepted as $\mathrm{p}<.05$. Effect sizes were calculated using Cohen's d.

\section{Results}

\section{Heart rate and RPE}

There were no significant differences between the supplements for mean HR values, before the exercise $\left(\mathrm{F}_{(2,12)}=.400 ; \mathrm{p}=.679\right)$ as well as during the $60 \mathrm{~min}$ experimental trials $\left(\mathrm{F}_{(2,12)=} 380 ; \mathrm{p}=692\right)$. Furthermore, mean HR values did not change significantly over the $60 \mathrm{~min}$ exercise period, irrespective of the supplement $\left(\mathrm{F}_{(1.815,10.891)}=1.083 ; \mathrm{p}=.366\right)$.

Figure 2 demonstrates the mean heart rate values over time (every $10 \mathrm{~min}$ ), including the resting data, for each supplement. Mean HR values over the $60 \mathrm{~min}$ walk were significantly higher, compared to the resting values (mean difference $=46 \mathrm{bpm} ; \mathrm{p}<.001$ ), for all the supplements. RPE increased by 2 on the RPE scale, over the 60min treadmill walk $\left(\mathrm{F}_{(1.176,7.056)}=5.658 ; \mathrm{p}=.045\right)$, but there were no significant differences across the experimental conditions, either as main effect $\left(\mathrm{F}_{(1.127,6.765)}=1,829 ; \mathrm{p}=.223\right)$, or as an interaction with time $\left(\mathrm{F}_{(2.716,16.294)}=1.408 ; \mathrm{p}=.276\right)$.

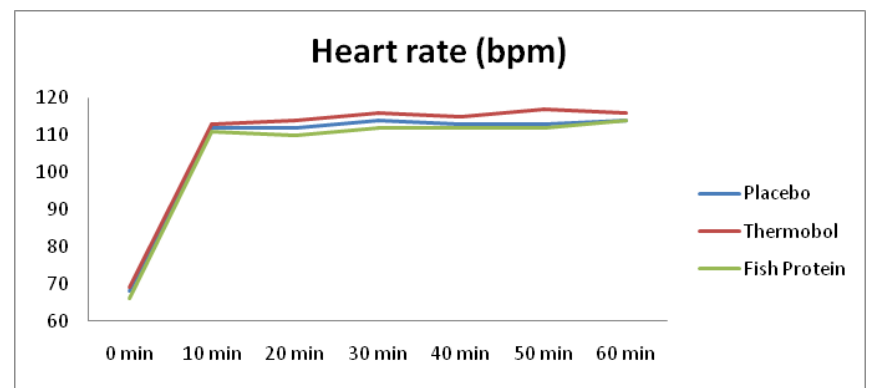

Figure 2 Mean HR values at rest and over the 60-min treadmill walk timecourse for the three experimental conditions.

\section{Blood glucose and lactate}

Figures $3 \& 4$ indicate the mean blood glucose $\left(\mathrm{mmol} \mathrm{L}^{-1}\right)$ and lactate $\left(\mathrm{mmol} \mathrm{L}^{-1}\right)$ responses at four different time points $\left(\mathrm{t}_{1}=0, \mathrm{t}_{2}=10\right.$, $t_{3}=30$ and $t_{4}=50 \mathrm{~min}$ ), for each of the three supplements. There was a significant main effect of time for blood glucose $\left(\mathrm{F}_{(3,15)}=15.530\right.$; $\mathrm{p}<.001$ ), where it decreased by an average of $0.42 \mathrm{mmol} \mathrm{L}^{-1}$, over the $50 \mathrm{~min}\left(95 \% \mathrm{CI}=.15\right.$ to $\left..69 ; \mathrm{t}_{(5)}=3.984 ; \mathrm{p}=.01\right)$. No significant main effect for condition $\left(\mathrm{F}_{(2,10)}=3.377 ; \mathrm{p}=.076\right)$ as well as no significant interaction between condition and time $\left(\mathrm{F}_{(6,30)}=.718 ; \mathrm{p}=.638\right)$ was found.

The blood lactate concentrations did not differ significantly, neither across the three experimental conditions $\left(\mathrm{F}_{(2,10)}=2.770 ; \mathrm{p}=.110\right)$, nor over the four time points $\left(\mathrm{F}_{(3,15)}=2.464 ; \mathrm{p}=.102\right)$.

\section{Energy expenditure and substrate oxidation}

Figure 5 outlines the mean EE $\left(\mathrm{kcalmin}^{-1}\right)$ values, over the 60 min treadmill task, among the three supplements. A main effect for condition was observed for $\mathrm{EE}\left(\mathrm{F}_{(2,12)}=4.078 ; \mathrm{p}=.045\right)$, where the $\mathrm{EE}$ 
for Thermobol was $2.4 \%$ higher, compared to placebo [8.23 (1.39) Vs 8.03 (1.46); $\mathrm{p}=.042$; $\mathrm{E} . \mathrm{S}=.14$, power=.06], whereas mean $\mathrm{EE}$ in Nutripeptin $^{\mathrm{TM}}$ did not differ significantly, compared to placebo [8.21 (1.46) vs 8.03 (1.46); p=.073; E.S=.12; power=.06]. However, the main effect of time and the interaction between condition and time were not significant $\left(\mathrm{F}_{(1.762,10.571)}=.593 ; \mathrm{p}=.550, \mathrm{~F}_{(2.065,12.391)}=.833\right.$ $\mathrm{p}=.461)$.

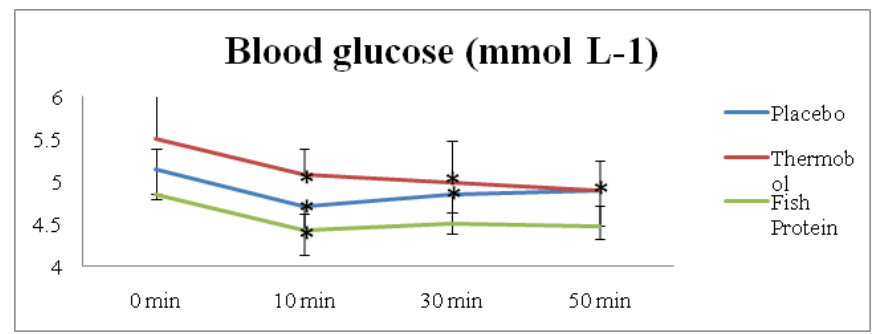

Figure 3 Mean blood glucose $\left(\mathrm{mmolL}^{-1}\right)$ at rest and over a 50-min treadmill walk period for the three experimental conditions.

Table 1 indicates the mean (S.D) fat oxidation rates, over the 60min treadmill task, for each of the three experimental conditions. Although, there was not found a significant main effect for condition $\left(\mathrm{F}_{(2,12)}=1.117 ; \quad \mathrm{p}=.359 ; \quad\right.$ E. $\mathrm{S}_{\mathrm{TB}-\mathrm{PL}}=.5 ; \quad$ power $=.20 ; \quad$ E. $\mathrm{S}_{\mathrm{NP}-\mathrm{PL}}=.06$; power $=.06)$, the main effect of time, regardless of the supplement, was discovered to be significant $\left(\mathrm{F}_{(5,30)}=14.850 ; \mathrm{p}<.001\right)$. Particularly, over the first $30 \mathrm{~min}$ of the exercise, the absolute fat oxidation rates decreased by approximately $.11 \mathrm{gmin}^{-1}\left(95 \% \mathrm{CI}=.06\right.$ to $.16 ; \mathrm{t}_{(6)}=5.422$; $\mathrm{p}=.002)$, whereas it increased by approximately $.04 \mathrm{gmin}^{-1}(95 \% \mathrm{CI}=-$ .08 to $\left.-.006 ; \mathrm{t}_{(6)}=-2.104 ; \mathrm{p}=.05\right)$, over the last $30 \mathrm{~min}$.

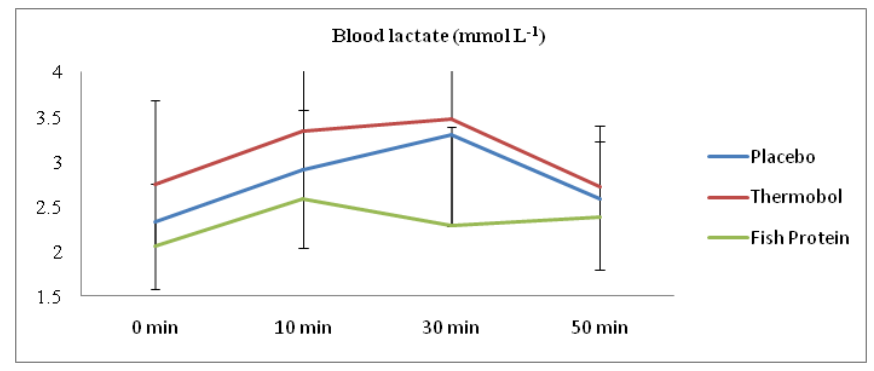

Figure 4 Mean blood lactate $\left(\mathrm{mmolL}^{-1}\right)$ at rest and over a 50-min treadmill walk period for the three experimental conditions.

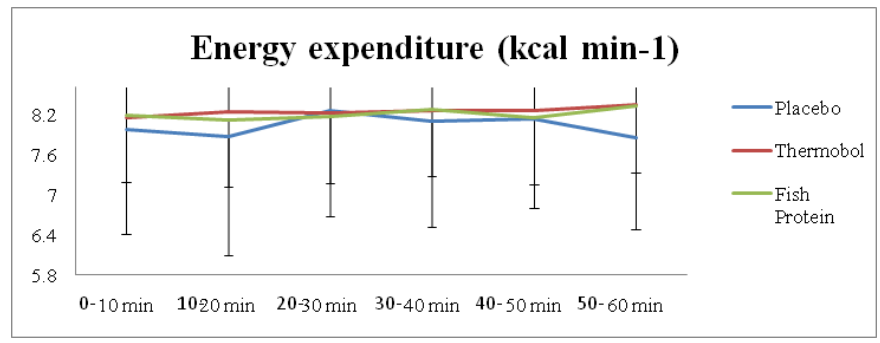

Figure 5 Mean EE $\left(\mathrm{kcal} \mathrm{min}^{-1}\right)$ over the $60 \mathrm{~min}$ treadmill walk, across the thee experimental conditions.

Table I Fat oxidation rates [mean (SD)] over the 60-min treadmill walk of 0-10, 10-20, 20-30, 30-40, 40-50, and 50-60min, for each of the three experimental conditions

\begin{tabular}{lllllll}
\hline \multicolumn{6}{l}{ FAT $\left(\mathrm{gmin}^{-1}\right)$} \\
\hline Time & $0-10$ & $20-$ Oct & $20-30$ & $30-40$ & $40-50$ & $50-60$ \\
Placebo & $.47(.20)$ & $.35(.19)$ & $.37(.17)$ & $.40(.17)$ & $.40(.16)$ & $.43(.11)$ \\
Thermobol & $.52(.16)$ & $.43(.14)$ & $.42(.15)$ & $.49(.19)$ & $.44(.13)$ & $.51(.16)$ \\
Fish Protein & $.48(.18)$ & $.37(.19)$ & $.36(.14)$ & $.40(.19)$ & $.40(.16)$ & $.46(.19)$ \\
\hline
\end{tabular}

Table 2 displays the mean (SD) carbohydrate oxidation rates, over the 60-min treadmill walk, for each of the three supplements. Similarly to fat, there was not a significant main effect for condition $\left(\mathrm{F}_{(2,12)}=.709\right.$; $\mathrm{p}=.512$; E. $\mathrm{S}_{\mathrm{TB}-\mathrm{PL}}=.4$; power $=.15$; E. $\mathrm{S}_{\mathrm{NP}-\mathrm{PL}}=.06$; power $\left.=.06\right)$, while the main effect of time, irrespective of the supplement, was found to be significant $\left(\mathrm{F}_{(5.30)}=18.063 ; \mathrm{p}<.001\right)$. Especially, over the first $30 \mathrm{~min}$ of the exercise, the absolute carbohydrate oxidation rates increased by approximately .26 gmin $^{-1}\left(95 \% \mathrm{CI}=-.37\right.$ to $\left.-.16 ; \mathrm{t}_{(0)}=-6.142 ; \mathrm{p}=.001\right)$, while they decreased by approximately $.1 \mathrm{gmin}^{-1}(95 \% \mathrm{CI}=.04$ to .15 ; $\left.\mathrm{t}_{(6)}=4.398 ; \mathrm{p}=.005\right)$, over the last $30 \mathrm{~min}$.

Table $2 \mathrm{CHO}$ oxidation rates [mean (SD)] over the $60 \mathrm{~min}$ treadmill walk of 0-10, 10-20, 20-30,30-40,40-50, and 50-60 min, for each of the three experimental conditions

\begin{tabular}{lllllll}
\hline \multicolumn{7}{l}{ CHO $\left(\mathrm{gmin}^{-1}\right)$} \\
\hline Time $(\mathrm{min})$ & $0-10$ & $20-$ Oct & $20-30$ & $30-40$ & $40-50$ & $50-60$ \\
Placebo & $.87(.3 \mathrm{I})$ & $1.1(.3 \mathrm{I})$ & $\mathrm{I} .16(.24)$ & $1.04(.23)$ & $1.05(.20)$ & $.90(.26)$ \\
Thermobol & $.79(.24)$ & $1.01(.29)$ & $1.03(.27)$ & $.89(.3 \mathrm{I})$ & $.99(.26)$ & $.86(.23)$ \\
Fish Protein & $.88(.38)$ & $1.12(.39)$ & $1.14(.39)$ & $1.08(.45)$ & $1.05(.44)$ & $.95(.47)$ \\
\hline
\end{tabular}

\section{Discussion}

The purpose of the current research study was to determine whether Thermobol, i.e. a commercially available 'fat-burner', and/or a fish protein hydrolysate (Nutripeptin ${ }^{\mathrm{TM}}$ ), could raise fat metabolism during submaximal exercise at the Fat ${ }_{\max }$ intensity, compared to a placebo. Fat ${ }_{\max }$ intensity has been defined as the exercise intensity at which maximal fat oxidation rates occur. ${ }^{31}$ Since during aerobic exercise, fat and $\mathrm{CHO}$ are the main energy substrates as well as their relative utilization depends predominantly upon the exercise intensity, ${ }^{32} \mathrm{Fat}_{\text {max }}$ intensity was selected for this study, so that any potential favorable effects of Thermobol and/or Nutripeptin ${ }^{\mathrm{TM}}$ on fat metabolism, might evidently emerge. Furthermore, the experimental trials performed at

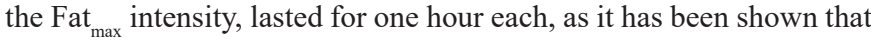


prolonged submaximal exercise, results in a time-dependent increase in fat oxidation and a decrease in $\mathrm{CHO}$ oxidation, respectively. ${ }^{33}$

The main finding of this study was that Thermobol, but not Nutripeptin $^{\mathrm{TM}}$, resulted in a significant increase in EE by $2.4 \%$, compared to the placebo. Furthermore, it was demonstrated that although absolute fat oxidation rates significantly decreased over the 60 -min of the exercise $\left(.02 \mathrm{gmin}^{-1}\right)$, absolute $\mathrm{CHO}$ oxidation rates significantly increased over that time $\left(.25 \mathrm{gmin}^{-1}\right)$, leading to an overall increment in $\mathrm{EE}$ by $.06 \mathrm{kcalmin}^{-1}$; however, this was non-significant $(p=.550)$. Heart rate, blood glucose and blood lactate responses were not found to be significantly different, contingent on the type of the supplement ingested.

It is well known that acute exercise enhances lipolysis and subsequent fatty acid mobilization and oxidation in the adipose and in the muscle tissue as well. ${ }^{34}$ Indeed, our participants exercise absolute fat oxidation rates $\left(\mathrm{gmin}^{-1}\right)$ were significantly higher than their resting ones (mean difference $=19.8 \mathrm{~g} \mathrm{~h}^{-1} ; \mathrm{p}<.001$, data not shown). This exercise-induced increment has been primarily attributed to elevated levels of the lipolytic catecholamines during exercise ${ }^{35}$ and small decreases in insulin concentration as well, which has been recognised as an anabolic hormone. ${ }^{36}$ However, recent data suggests that in obese men, atrial natriuretic peptide (ANP) is a more important stimulus of lipolysis. ${ }^{37}$

To our knowledge, only two previous studies have investigated the effect of a fish protein hydrolysate (Nutripeptin ${ }^{\mathrm{TM}}$ ) supplement on human metabolism, during exercise. Particularly, Vegge et al., ${ }^{29}$ did not demonstrate that the addition of Nutripeptin ${ }^{\mathrm{TM}}$ in a maltodextrinwhey protein solution (CHO-PRO-PEP) could bring on lower RER values, thus indicating a shift towards fat oxidation, compared to iso-caloric maltodextrin-whey protein (CHO-PRO) and maltodextrin $(\mathrm{CHO})$ solutions. On the other hand, Siegler et al. ${ }^{28}$ employed a very analogous experimental design to the aforementioned study, i.e. 90min submaximal cycling exercise instead of 120 -min, as well as the same supplements and reported significantly higher RER values in the CHO-PRO, compared to the $\mathrm{CHO}$ and the CHO-PRO-PEP solutions. The findings of our study agree with Vegge et al., ${ }^{29}$ observations, since the Nutripeptin ${ }^{\mathrm{TM}}$ supplement did not result in higher absolute fat oxidation rates $\left(\mathrm{gmin}^{-1}\right)$, compared to placebo. The lower RER values reported in Siegler et al., ${ }^{28}$ study in the CHO-PRO-PEP condition, compared to the CHO-PRO condition, could possibly be attributed to the participants' body composition, training status, feeding state or the formulation of the supplements themselves (different concentrations and solutions Vs tablets). In our study, we targeted sedentary obese males (mean BMI $=36.9 \mathrm{kgm}^{-2}$ ) who performed a 60 -min treadmill task 4hours postprandial, whereas Siegler et al., ${ }^{28}$ used normal BMI (mean $\left.\mathrm{BMI}=24.3 \mathrm{kgm}^{-2}\right)$ males who engaged in regular aerobic training (3-5 days week $\mathrm{k}^{-1}$ ), prior to and throughout the data collection period.

Furthermore, they were tested 12 hours postprandial. It has long been known that endurance exercise training increases fat oxidation during submaximal exercise, since it increases the capacity of skeletal muscle to oxidize fat. ${ }^{38}$ It is also known that exercising in the nonfasted state (postprandial or post absorptive), results in a suppression of FFA supply into plasma and thus their availability for oxidation in the contracting muscles. ${ }^{39}$ Finally, obese people have been shown to have a decreased capacity to oxidize fat ${ }^{40}$ and especially lipids within the skeletal muscle. ${ }^{41}$ Therefore, it is likely that any of these reasons could have moderated any potential favorable effects of Nutripeptin ${ }^{\mathrm{TM}}$ on fat metabolism in our study, especially during a state where fat metabolism is already stimulated (exercise). ${ }^{13}$
Even though Thermobol's ingredients, especially caffeine and GTE, have consistently been shown to be capable of increasing EE and fat oxidation, ${ }^{4}$ there still are some research studies, which do not support these outcomes, particularly in terms of fat metabolism. Catechins found in green tea extracts, exert their stimulatory actions in the SNS and thus thermogenesis and fat oxidation, via the catechol-O-methyltransferase (COMT) enzyme pathway. Notably, catechins inhibit COMT which is responsible for the degradation of norepinephrine (NE). As a result, NE remains active in the synaptic cleft, continuously stimulating the SNS. ${ }^{3}$ Furthermore, catechins can directly act upon the gene expression of the uncoupling proteins (UCPs), which are responsible for the production of heat in the mitochondria. ${ }^{4}$ On the other hand, caffeine has been proposed to affect thermogenesis, by inhibiting the enzyme phosphodiesterase which degrades intracellular cyclic amino-mono-phosphate (cAMP). This leads to an increase in cAMP concentration and subsequently to an elevated SNS activity. ${ }^{3}$ This cascade of events also activates the lipolytic hormone-sensitive lipase, resulting in increased fat oxidation. $^{4}$

In this study we found that Thermobol significantly increases EE, compared to placebo [(8.24 (1.39) Vs 8.03 (1.46); $\mathrm{p}=.043$ ], finding which agrees with most of the studies which have tested caffeine and GTE, either individually or as a mixture. ${ }^{6,9,12,42}$ Although absolute fat oxidation rates were greater, compared to placebo, this difference was not significant $(\mathrm{p}=.359)$. Our findings agree with several studies which have employed similar supplements. Gregersen et al., ${ }^{3}$ did not find significantly lower fat oxidation rates $\left(\mathrm{g} 12.5 \mathrm{~h}^{-1}\right)$, following caffeinecatechins mixtures (25mg caffeine/101.2mg EGCG) ingestion, compared to placebo ( $84.8 \mathrm{Vs} 76.8, \mathrm{p}=.55)$. Additionally, Hill et al., ${ }^{16}$ and Maki et al., ${ }^{1}$ did not find that the long-term supplementation (12weeks) with EGCG in overweight/obese adults, superimposed on a regular moderate-intensity exercise programme, can increase the oxidation of fat mass, compared to placebo. However, Venables et al., ${ }^{13}$ investigated the effects of acute GTE ingestion (day before and just before exercise, $366 \mathrm{mg} \mathrm{d}^{-1}$ EGCG) on substrate metabolism, during moderate-intensity exercise and found that fat oxidation rates were significantly higher $(17 \%, \mathrm{p}<.05)$ following GTE ingestion, compared to placebo. Furthermore, Hursel et al., ${ }^{11}$ meta-analysis demonstrated that catechin-caffeine mixtures increase fat oxidation, compared to placebo.

The caffeine and GTE dosages administered prior to exercise in this study, were $459 \mathrm{mg}$ and $300 \mathrm{mg}$, respectively. These dosages have been shown to be almost optimal to increase fat oxidation ${ }^{12}$ and various studies have used similar dosages with positive outcomes on EE and fat oxidation. ${ }^{10,11,28}$ As a result it does not seem possible that the dosage of the Thermobol supplement was not sufficient to exert any potential stimulatory effects on fat oxidation. However, the fact that we administered Thermobol in obese males, who have impaired fat oxidation capacity, ${ }^{40}$ over an exercise bout, when fat metabolism is already stimulated, ${ }^{13}$ may have masked the metabolic effects of Thermobol. Apart from that, some of our participants may have been high-caffeine consumers and thus not sensitive to the effects of green tea and caffeine. ${ }^{7}$

Blood glucose and lactate did not differ significantly across the experimental conditions and this finding is in line with previous studies which have employed similar supplements. Siegler et al., ${ }^{28}$ as well as Vegge et al., ${ }^{29}$ did not report overall differences in blood lactate and glucose concentrations between the $\mathrm{CHO}, \mathrm{CHO}-\mathrm{PRO}$ and the CHO-PRO-PEP supplements. As a result, it may not be likely that an FPH supplement impacts differently upon glucose and lactate 
responses, compared to a placebo. Venables et al. ${ }^{13}$ demonstrated that blood glucose concentration was unaffected by the acute ingestion of GTE, prior to submaximal cycling exercise performance, although there was a decrease over the 30 -min of cycling $\left(.5 \mathrm{mmol} \mathrm{L}^{-1}, \mathrm{p}=.01\right)$. A significant decrease of blood glucose concentration over the exercise period was discovered in this study $\left(.42 \mathrm{mmol} \mathrm{L}^{-1}\right.$ reduction $)$ and in Siegler et al. ${ }^{28}$ study (decrease by an average of $.3 \mathrm{mM}$ ) as well. Conversely, Hill et al., ${ }^{16}$ detected significantly lower concentrations of blood glucose after 12 weeks of daily EGCG supplementation $(300 \mathrm{mg})$ along with regular exercise, compared to placebo [5.52 (.06) Vs $5.3(.1), \mathrm{p}<.05]$. They concluded that green tea catechins may lower plasma glucose by increasing the uptake and translocation of the GLUT4 protein in skeletal muscles. Therefore, in our study we may have found lower blood glucose concentrations in the Thermobol condition, compared to placebo, if the supplementation lasted longer. The effect of Thermobol's ingredients on blood lactate responses are obscure, since most of the studies which have tested the metabolic effects of such constituents in humans, have not quantified blood lactate concentrations.

There is no evidence that an FPH supplement may act differently on HR responses, compared to a placebo, ${ }^{28,29}$ which is pursuant to our results. Similarly, Thermobol did not result in significantly different HR responses, compared to placebo, finding which agrees with most of the studies which have tested some of the Thermobol's ingredients, either individually or in combination. ${ }^{42}$ However, Gregersen et al., ${ }^{3}$ reported decreased resting HR values, following an acute EGCG treatment, compared to placebo. They concluded that since EGCG is likely to increase EE, through the activation of the sympathetic nervous system (SNS), someone would expect an increase in HR, finding which has not been confirmed to date though.

The major limitation of this study is its small statistical power which could have led to type II errors, i.e. to accepting the Ho (no significant differences), when actually it is erroneous. The lack of statistical power which may have masked significant effects in this study, derives from a small sample size $(\mathrm{n}=7)$ as well as small effect sizes between the variables, compared against each other. The large measurement variability (large S.D.) detected, is accountable to the small effect sizes obtained. Furthermore, the fact that we could not control the degree to which the participants complied to the dietary and exercise guidelines that were provided with, may undermine the results. Lastly, we did not assess the effect of our participants' chronic dietary habits on our results. Scientific research has demonstrated that high-carbohydrate diets result in reduced fat oxidation during exercise whereas high-fat diets lead to increased fat oxidation capacity. ${ }^{43}$

\section{Conclusion}

In summary, our study gives support to the hypothesis that NutripeptinTM may not be capable of increasing fat oxidation rates during submaximal exercise at the Fat ${ }_{\max }$ intensity, in obese males at the postprandial state. Although Thermobol is likely to exert this effect, it was not demonstrated in this study, possibly because of small effect sizes, a small sample size and thus undersized statistical power. Even though many studies have suggested pathways through which Thermobol's ingredients could result in elevated EE and fat oxidation rates, the mechanisms of Nutripeptin's possible metabolic effects are unknown. To further elucidate its effects of on fat metabolism during exercise, further investigations are warranted which will also encompass in vitro experiments, in an effort to uncover the mechanisms, through which this supplement may act on exercise metabolism.

\section{Acknowledgements}

None.

\section{Conflict of interest}

The author declares no conflict of interest.

\section{References}

1. Maki KC, Reeves MS, Farmer M, et al. Green tea catechin consumption enhances exercise-induced abdominal fat loss in overweight and obese adults. J Nutr. 2009;139(2):264-270

2. Smeets AJ, Westerterp-Plantenga MS. The acute effects of a lunch containing capsaicin on energy and substrate utilization, hormones, and satiety. Eur J Nutr. 2009;48(4):229-234.

3. Gregersen NT, Bitz C, Krog-Mikkelsen I, et al. Effect of moderate intakes of different tea catechins and caffeine on acute measures of energy metabolism under sedentary conditions. Br J Nutr. 2009;102(8):11871194.

4. Hursel R, Westerterp-Plantenga MS. Thermogenic ingredients and body weight regulation. Int J Obes (Lond). 2010;34(4):659-669.

5. Jeukendrup AE, Randell R. Fat burners: nutrition supplements that increase fat metabolism. Obes Rev. 2011;12(10):841-851.

6. Belza A, Jessen AB. Bioactive food stimulants of sympathetic activity: effect on 24-h energy expenditure and fat oxidation. Eur J Clin Nutr. 2005;59(6):733-741.

7. Belza A, Toubro S, Astrup A. The effect of caffeine, green tea and tyrosine on thermogenesis and energy intake. Eur J Clin Nutr. 2009;63(1):57-64.

8. Mercader J, Wanecq E, Chen J, et al. Isopropylnorsynephrine is a stronger lipolytic agent in human adipocytes than synephrine and other amines present in Citrus aurantium. J Physiol Biochem. 2011;67(3):443-452.

9. Bérubé-Parent S, Pelletier C, Doré J, et al. Effects of encapsulated green tea and Guarana extracts containing a mixture of epigallocatechin-3gallate and caffeine on $24 \mathrm{~h}$ energy expenditure and fat oxidation in men. Br J Nutr. 2005;94(3):432-436.

10. Miles-Chan JL, Charrière N, Grasser EK, et al. The thermic effect of sugar-free red bull: Do the non-caffeine bioactive ingredients in energy drinks play a role? Obesity. 2015;23(1):16-19.

11. Hursel R, Viechtbauer W, Dulloo AG, et al. The effects of catechin rich teas and caffeine on energy expenditure and fat oxidation: a metaanalysis. Obes Rev. 2011;12(7):e573-e581.

12. Thielecke F, Rahn G, Böhnke J, et al. Epigallocatechin-3-gallate and postprandial fat oxidation in overweight/obese male volunteers: a pilot study. Eur J Clin Nutr. 2010;64(7):704-713.

13. Venables MC, Hulston CJ, Cox HR, et al. Green tea extract ingestion, fat oxidation, and glucose tolerance in healthy humans. Am J Clin Nutr. 2008;87(3):778-784.

14. Ota N, Soga S, Shimotoyodome A, et al. Effects of combination of regular exercise and tea catechins intake on energy expenditure in humans. Journal of Health Science. 2005;51(2):223-236.

15. Boschmann M, Thielecke F. The effects of epigallocatechin-3-gallate on thermogenesis and fat oxidation in obese men:a pilot study. $J$ Am Coll Nutr. 2007;26(4):389-395.

16. Hill AM, Coates AM, Buckley JD, et al. Can EGCG reduce abdominal fat in obese subjects? J Am Coll Nutr. 2007;26(4):396-402.

17. Lejeune MP, Kovacs EM, Westerterp-Plantenga MS. Effect of capsaicin on substrate oxidation and weight maintenance after modest bodyweight loss in human subjects. Br J Nutr. 2003;90(3):651-659. 
18. Ludy MJ, Mattes RD. The effects of hedonically acceptable red pepper doses on thermogenesis and appetite. Physiol Behav. 2011;102(34):251-258.

19. Shin KO, Moritani T. Alterations of autonomic nervous activity and energy metabolism by capsaicin ingestion during aerobic exercise in healthy men. J Nutr Sci Vitaminol (Tokyo). 2007;53(2):124-132.

20. Ahuja KD, Robertson IK, Geraghty DP, et al. The effect of 4-week chilli supplementation on metabolic and arterial function in humans. Eur $J$ Clin Nutr. 2007;61(3):326-333.

21. Lee JK, Jeon JK, Kim SK, et al. Characterization of bioactive peptides obtained from marine invertebrates. In: Se-Kwon K, editor. Advances in Food and Nutrition Research-Marine Medicinal Foods: Implications and Applications-Animals and Microbes. 1st ed. UK: Academic Press; 2012. $280 \mathrm{p}$

22. Vidanarachchi JK, Kurukulasuriya MS, Malshani SA, et al. Applications of marine nutraceuticals in dairy products. In: Se-Kwon K, editor. Advances in Food and Nutrition Research-Marine Medicinal Foods. Implications and Applications-Animals and Microbes. UK: Academic Press; 2012. p. 457-478.

23. Lordan S, Ross RP, Stanton C. Marine bioactives as functional food ingredients: potential to reduce the incidence of chronic diseases. Mar Drugs. 2011;9(6):1056-1100.

24. Giri A, Ohshima T. Bioactive marine peptides: nutraceutical value and novel approaches. In: Se-Kwon K, editor. Advances in Food and Nutrition Research-Marine Medicinal Foods: Implications and Applications-Animals and Microbes. UK: Academic Press; 2012. p. 73-105.

25. Harnedy PA, FitzGerald RJ. Bioactive peptides from marine processing waste and shellfish: A review. Journal of Functional Foods. 2012;4(1):624.

26. Ngo DH, Vo TS, Ngo DN, et al. Biological activities and potential health benefits of bioactive peptides derived from marine organisms. Int J Biol Macromol. 2012;51(4):378-383.

27. Liaset B, Madsen L, Hao Q, et al. Fish protein hydrolysate elevates plasma bile acids and reduces visceral adipose tissue mass in rats. Biochim Biophys Acta. 2009;1791(4):254-262.

28. Siegler JC, Page R, Turner M, et al. The effect of carbohydrate and marine peptide hydrolysate co-ingestion on endurance exercise metabolism and performance. J Int Soc Sports Nutr. 2013;10(1):29.

29. Vegge G, Rønnestad BR, Ellefsen S. Improved cycling performance with ingestion of hydrolysed marine protein depends on performance level. J Int Soc Sports Nutr. 2012;9(1):14.
30. Venables MC, Achten J, Jeukendrup AE. Determinants of fat oxidation during exercise in healthy men and women: a cross-sectional study. $J$ Appl Physiol (1985). 2005;98(1):160-167.

31. Achten J, Gleeson M, Jeukendrup AE. Determination of the exercise that elicits maximal fat oxidation. Med Sci Sports Exerc. 2002;34(1):92-97.

32. Chenevière X, Malatesta D, Gojanovic B, et al. Differences in wholebody fat oxidation kinetics between cycling and running. Eur J Appl Physiol. 2010;109(6):1037-1045.

33. Chenevière $\mathrm{X}$, Borrani $\mathrm{F}$, Ebenegger $\mathrm{V}$, et al. Effect of a 1-hour single bout of moderate-intensity exercise on fat oxidation kinetics. Metabolism. 2009;58(12):1778-1786.

34. Thompson D, Karpe F, Lafontan M, et al. Physical activity and exercise in the regulation of human adipose tissue physiology. Physiol Rev. 2012;92(1):157-191.

35. Yardley JE, Kenny GP, Perkins BA, et al. Effects of performing resistance exercise before versus after aerobic exercise on glycemia in type 2 diabetes. Diabetes Care. 2012;35(4):699-675.

36. Dunstan DW, Kingwell BA, Larsen R, et al. Breaking up prolonged sitting reduces postprandial glucose and insulin responses. Diabetes Care. 2012;35(5):976-983.

37. Koppo K, Larrouy D, Marques MA, et al. Lipid mobilization in subcutaneous adipose tissue during exercise in lean and obese humans. Roles of insulin and natriuretic peptides. Am J Physiol Endocrinol Metab. 2010;299(2):E258-E265.

38. Melanson EL, Gozansky WS, Barry DW, et al. When energy balance is maintained, exercise does not influence negative fat balance in lean sedentary, obese sedentary, or lean endurance-trained individuals. $J \mathrm{Appl}$ Physiol (1985). 2009;107(6):1847-1856.

39. Kiens B. Skeletal muscle lipid metabolism in exercise and insulin resistance. Physiol Rev. 2006;86(1):205-243.

40. Achten J, Jeukendrup AE. Optimizing fat oxidation through exercise and diet. Nutrition. 2004;20(7-8):716-727.

41. Venables MC, Jeukendrup AE. Endurance training and obesity: effect on substrate metabolism and insulin sensitivity. Med Sci Sports Exerc. 2008;40(3):495-502.

42. Rudelle S, Ferruzzi MG, Cristiani I, et al. Effect of a thermogenic beverage on 24-hour energy metabolism in humans. Obesity. 2007;15(2):349-355.

43. TransJeukendrup AE. Modulation of carbohydrate and fat utilization by diet, exercise and environment. Biochem Soc. 2003;31(6):1270-1273. 